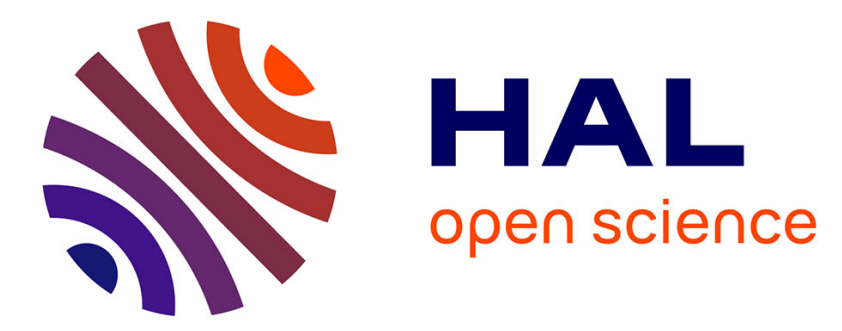

\title{
Handling effective communication to support awareness in rescue operations
}

\author{
Samer Chehade, Nada Matta, Jean-baptiste Pothin, Rémi Cogranne
}

\section{To cite this version:}

Samer Chehade, Nada Matta, Jean-baptiste Pothin, Rémi Cogranne. Handling effective communication to support awareness in rescue operations. Journal of Contingencies and Crisis Management, 2020, Knowledge, Semantics and AI for Risk and Crisis Management, 28 (3), pp.307-323. 10.1111/14685973.12317. hal-02955866

\section{HAL Id: hal-02955866 \\ https://hal-utt.archives-ouvertes.fr/hal-02955866}

Submitted on 2 Oct 2020

HAL is a multi-disciplinary open access archive for the deposit and dissemination of scientific research documents, whether they are published or not. The documents may come from teaching and research institutions in France or abroad, or from public or private research centers.
L'archive ouverte pluridisciplinaire HAL, est destinée au dépôt et à la diffusion de documents scientifiques de niveau recherche, publiés ou non, émanant des établissements d'enseignement et de recherche français ou étrangers, des laboratoires publics ou privés. 


\title{
Handling Effective Communication to Support Awareness in Rescue Operations
}

\author{
Samer Chehade $\dagger *$, Nada Matta†, Jean-Baptiste Pothin*, and Remi Cogranne $\dagger$ \\ † Institut Charles Delaunay, FRE 2019 CNRS, TechCICO / M2S, University of Technology of Troyes, 12 rue Marie Curie, CS 42060 - \\ 10004 Troyes Cedex, France, \{ samer.chehade, nada.matta, remi.cogranne\}@utt.fr \\ * Department of Research \& Development, DataHertz, Technopole de l'Aube en Champagne, 6 rue Gustave Eiffel, 10430 Rosières-près- \\ Troyes, France, \{ samer.chehade, jean-baptiste.pothin $\} @$ datahertz.fr
}

Running head: Effective Communication in Rescue Operations

\author{
Corresponding Author: Samer Chehade \\ Address: University of Technology of Troyes 12 rue Marie Curie CS 42060 - 10004 Troyes Cedex, France \\ Email address: samer.chehade@datahertz.fr / samer.chehade@utt.fr \\ Phone number: +33 325759716 \\ Mobile: +33646874802 \\ Number of pages: 25
}

\section{Acknowledgement}

The authors would like to thank the National Association for Research and Technology (ANRT) in France for funding this work.

Conflict of Interest: None. 


\title{
Handling Effective Communication to Support Awareness in Rescue Operations
}

\begin{abstract}
Efficient rescue operations require a high level of situation awareness among decision-makers and first responders for the purpose of achieving operations successfully and reducing losses. Moreover, a common operational picture between involved actors is required in order to support decision-making. Therefore, different organisations and agencies have to collaborate, cooperate and coordinate their actions with each other. Hence, effective interactions and communications between participants are vital to fulfil these essential needs. However, emergency actors still lack backing to exchange information effectively and ensure a common operational picture in order to reach shared situational awareness. For this reason, we aim to develop and implement Rescue MODES, a communication system oriented to support situation awareness amongst French emergency actors in rescue operations. In this paper, we examine and analyse actors' activities and interactions, so that the system will be based on the real needs of actors. We start by studying and modelling the communications, interactions, and information flow. This modelling is based on an application ontology. Then, we define requirements for good communication in these operations and present some existing systems in France and how each system responds to these requirements.
\end{abstract}

Keywords - Communication requirements, Emergency Services, Interactions, Modelling, Ontologies, Rescue operations, Situation Awareness

\section{INTRODUCTION}

In his lifetime, each person is exposed to pass through distress situations due to particular events. Whether they are of smallscale such as car accidents and trauma or of large-scale like natural disasters or terrorist attacks, these events require responsive operations called rescue operations. Rescue operations consist in saving properties and victims' lives and by involving public organisations as well as private ones. In France, many public services are involved in such operations. They have to protect victims by ensuring their safety, securing scenes, providing first aids, and arranging transportation and evacuation to a relevant place of reception (Cazeneuve \& Touraine, 2015). Rescuers from various organisations have to collaborate with each other in order to achieve successful operations. In this context, they need to cooperate, reach and understand situations properly. Moreover, each participant must be aware of the situations and activities of others despite the location of each one. Therefore, it is necessary to handle efficiently information exchange in order to maintain a real-time operational picture for responders. However, the ability to quickly gather, fuse, and exchange relevant information is still a challenge. An enormous information flow has to be managed and most of the decisions are made based on this information. This complexity and information flow may lead to inefficient interactions between different actors, which can influence collaboration and situation awareness. Authors in (Saoutal et al., 2014) reported that ineffective communication between actors can lead to misunderstanding and misinterpretation of a situation, which can cause a lack of awareness about it and affect victims' safety. Assessments from many real incidents underline challenges of unsuccessful information exchange between engaged responders and their consequences on the operations' outcomes. For example, concluding reports on the terror attacks on November 13, 2015, in France, revealed major communication issues between different services. According to this report, each service focused on its own information and several victims on two different sites were not evacuated on time due to a lack of coordination (Fenech \& Pietrasanta, 2016). Consequences of communication problems are not limited to those regarding the victims' lives. In some cases, these problems can threaten the actors themselves. On September 4, 2018, a French firefighter was killed in Paris by an unstable victim during his evacuation. The reason behind this accident was a lack of communication between medical services and firefighters: "During the call transfer, medical services did not provide sufficient information about the seriousness of the situation" stated the firefighters chief (Décugis \& Pelletier, 2018).

To deal with these challenges, we propose to support communications and interactions between different actors in order to reinforce situation awareness. Hence, we look forward to design and implement a communication system aiming to simplify information sharing in rescue operations. This system is referred to as MODES that stands for Medical and Operational Data Exchange System for Rescue Operations. In order to be used by operational units for the support of their tasks, it is badly required to study and analyse actors' activities and interactions. We thus model in this paper interactions between actors and propose modelling requirements. In addition, we propose communication requirements to be ensured by the system based on the obtained model. The aim of passing through these steps is to propose a usable system based on real stakeholders' needs.

The remainder of this paper is divided into six sections. In section II, we provide more details on situation awareness, interactions, and communication problems in rescue operations. Section III discusses the related work and reviews the state of the art. In section IV, we describe rescue operations in France and present rescue interaction model. Then, in section V, we 
discuss the practical requirements that a communication system needs to fulfil in an operational context. Eventually, section VI concludes the paper.

\section{AWARENESS, INTERACTIONS, AND COMMUNICATION PROBLEMS}

In rescue operations, establishing a high level of situation awareness is fundamental to lessen undesirable consequences. Situation awareness was described as perceiving the practices of others, which gives a setting for your own practices (Dourish \& Bellotti, 1992). Another definition was proposed by Endsley in which she specified three required steps toward attaining situational awareness (Endsley, 2001). The first step requires perceiving all relevant factors that feature a situation together with their status and dynamics. The second step involves the comprehension of these factors, their senses, and relations, while the third step consists in predicting about the situation's evolution in the near future. Therefore, situation awareness can be expressed as the outcome of knowing what is going on around and serves as the foundation for decision-making. Unfortunately, reaching a high level of situation awareness is one of the most problematic duties in many activities and one of the most challenging tasks for rescue actors (Chehade et al., 2019). It requires managing diverse activities such as interaction and communication. Handling effective communications is mandatory in rescue operations since it is the only way to establish a common operational picture between actors through exchanging information about situations, casualties, resources, and locations. By sharing these and many other information, a common background about the on-going operation can be shared by all actors, which essentially consists of the two first steps of the aforementioned definition. However, handling effective communication in rescue operations remains a challenging problem. Several recent studies reveal persistent communication problems in rescue and emergency response domains (Steen-tveit \& Radianti, 2019). This is due to many reasons. First of all, the most common difficulty is the highly dynamic aspect of contexts and situations. Consequently, a continuous communication has to be maintained, which entails a large amount of information to be transmitted, derived and processed. Second, effective communication requires a common interpretation of the information by different entities. In rescuing, it is difficult to meet this requirement since each operation requires the engagement of multiple actors. Everyone involved has his own professional background and experience level. Finally, information exchanged during those operations can take different forms and types. For example, it can be in the form of texts, photos, audios or videos and it can be operational, spatial, and medical. This heterogeneity in data types and forms makes the activity of actors difficult. Figure 1 shows an example of a rescue operation case after a car accident causing casualties. Derived from French practices, this example shows that several organisations and actors are engaged in a single rescue operation. As we can see in this figure, these actors execute their tasks and communicate an enormous volume of information like medical and operational information.

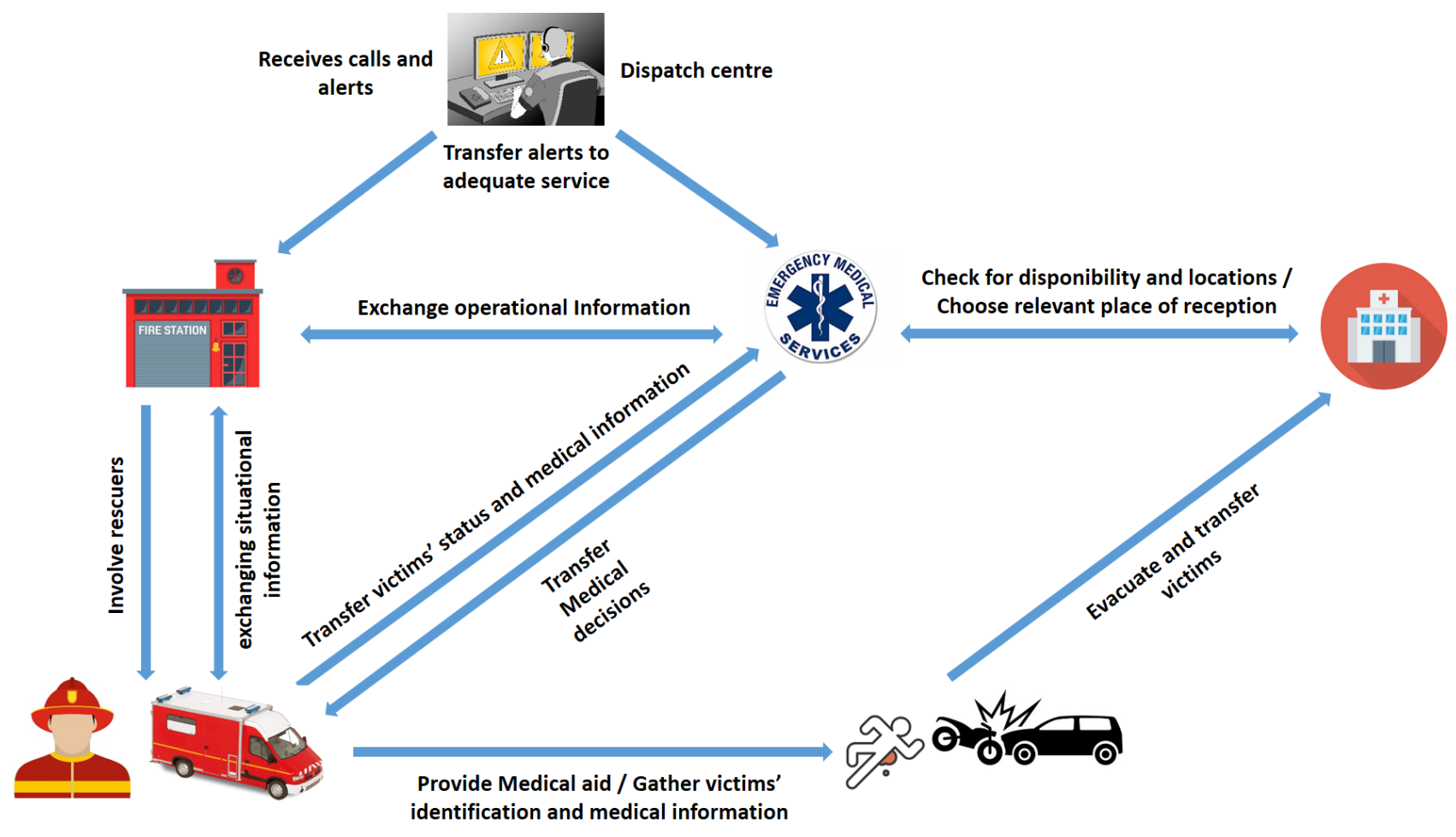

Figure 1: Information flow and involved actors in a rescue operation

All the aforementioned difficulties in situation awareness lead us to choose supporting interactions and communications in rescue operations. 


\section{RELATED WORK}

The improvement of communication and information sharing in rescue operations has been the topic of numerous studies over the past decades. Numerous solutions have been developed attempting to solve serious problems that lead to inefficient decision-making such as lack of situation awareness and inefficiency in information sharing. In this context, several systems were developed to support information exchange and communication. (Meissner et al., 2006) proposed MiKoBOS a system that aims at ensuring a reliable data exchange between different locations during emergency responses. The proposed system enables rescue teams to share operational information such as situation reports and available resources. However, medical information about victims, which is an important parameter in rescuing, was not considered in this system. Similarly, (Mallek et al., 2016) proposed an information exchange system to be implemented in French ambulances. The objective of this solution was to facilitate exchanges between medical regulators in hospitals and intervention teams on sites during victims' evacuation and transportation. However, this system focuses on medical information without taking into account other important information to be exchanged in rescue operations such as contextual and operational information. Moreover, several studies have been carried out to improve situation awareness in rescue operations. Some researchers worked on identifying information needs as a first step toward supporting communication and awareness. For instance, a study was conducted in (Yang et al., 2009) to identify information requirements for emergency response according to actors' roles. Unfortunately, identified requirements were limited to those related to on-site responders without considering other actors' needs. Other researchers chose to support awareness in such operations by using ontologies. For example, an ontology-based system was proposed in (Javed et al., 2011) to support team situation awareness by unifying situation understanding between participants. Moreover, a domain ontology has been proposed. However, the obtained ontology does not include concepts related to victims and medical information. In the same context, a first study was done by (Chehade et al., 2018, 2019) that aimed to support communication and data interpretation and thus to enhance awareness in rescue operations. To this end, an application ontology, called ResOnt, was proposed. However, the presented work was limited to the creation of the ontology.

On the other hand, research on modelling processes, communications, and interactions in emergency response and rescuing has evolved lately. Some researchers used methodologies based on business process modelling techniques and diagrams. (Saoutal et al., 2014) conducted a study to determine problems related to information exchange in inter-organisational emergency response. They also modelled communication between different stakeholders by using UML diagrams. One limitation of the proposed model is that it does not show the destinations and sources of information. In the same context, (Nunavath \& Prinz, 2015) choose to model the emergency management process in Norway by using Business Process Modelling Notation. This work aimed at supporting coordination and information sharing between different stakeholders involved in emergency response. To this end, an emergency management model was proposed showing the sequence of different tasks together with the responsible stakeholder. Unfortunately, the requirements for each participating actor in terms of information were not taken into consideration in the aforementioned model. Hence, the proposed model cannot serve as a basis for analysing and formalising interactions between different actors. Other studies were based on methodologies oriented for agent architectures. A recent study was conducted by (Chaawa et al., 2017) to model crisis management procedures and interactions between different actors in order to propose a flexible and usable crisis management system. To this end, three different models were proposed based on the GAIA methodology (Wooldridge et al., 2000) oriented for multi-agent architectures. The first model is an environmental model that identifies different concepts related to crisis management such as infrastructures and resources together with the information related to each concept. The second model is a role model that includes different tasks with the associated responsible actor. This model also highlights the various tasks that require interactions between different actors. While the third model is an interaction model that illustrates communications between different actors. Unfortunately, the information flow between different actors is not shown in the interaction model. Moreover, the role model does not illustrate the sequence of different tasks. In addition, dependencies between tasks and information and those between the roles of actors and information are not shown in any of these models. Therefore, the use of these models is limited and requires further analysis.

Yet, in most of the countries, communication during rescue operations is still limited to oral communication using radio devices. Regarding the French case, despite the large number of existing communication systems that are oriented for rescue actors (Appligos, n.d.-a, n.d.-b, n.d.-c; Nomadeec, n.d.; Mallek et al., 2016; Séguret, 2018; Sis, n.d.-a, n.d.-b; Systel, n.d.; TplSystemes, n.d.), recent statistics show that the majority of information exchange is still oral (Mallek et al., 2016). Indeed, most of the existing systems are not fully accepted by actors since they are limited to some functionalities or are developed without examining the real needs of actors. In addition, a lack of interoperability between the different existing systems is underlined, which makes the use of these systems more complicated (Elmhadhbi et al., 2018). Moreover, none of these systems meets all the identified requirements for effective communication. Further details are given in section V. In our opinion, the main reason behind this problematic is that the definition of interaction and data flows in rescue operations is not complete. Subsequently, the information that an actor is assumed to provide and receive is not clear. To deal with these issues, we introduce a communication system to support participant actors, namely Rescue MODES. We analyse interactions and communications and model them based on several parameters. An application ontology related to rescue is used to support the model as a source of main concepts. More details about these elements are discussed in Section IV. Moreover, we identify essential requirements for a good communication in rescue operations. In addition, we present several existing communication systems used by French actors, and we show how each system meets these requirements based on their specifications. 


\section{MODELLING INTERACTIONS AND COMMUNICATIONS}

As mentioned above, our aim is to design and implement an information sharing and communication system for rescue operations in France. To this end, a key first step consists in analysing communications and interactions in these operations through the study of documents, reports, and legislation related to the domain. This study allows us to identify different services as well as their missions, to analyse procedures, and to link these missions with interactions. In addition, we identify required elements and parameters to be taken into account when modelling interactions in complex contexts such as rescue operations and we propose a structure model. In this section, we give more details about rescue operations in France: The services involved and their missions. After that, we present requirements for modelling interactions and the used ontology to define them. Eventually, based on this ontology, an interaction model is proposed and presented in detail.

\section{A. Rescue operations in France: Involved services}

Before analysing any activity or procedure, it is fundamental to identify actors and services that are involved in these activities. Moreover, this process of comprehensive identification is also the basis for modelling communications since it identifies different entities that handle these communications and interactions. In France, rescue operations are missions of firefighters known as Local Services for Fire and Rescue (SDIS), and medical services so-called Urgent Medical Assistance Services (SAMU). A detailed referential has been published by the French state to clarify missions and responsibilities (Cazeneuve \& Touraine, 2015). SDIS are responsible for securing, protecting, firefighting, evacuating and transporting victims, while SAMU are asked to provide medical help for victims in emergencies. In addition, a detailed description of the organisation and hierarchy of each service is presented in this referential. Each SDIS and SAMU is composed of several centres and services that manage distinct tasks and duties. For example, a SDIS is composed of several Call Processing Centres (CTA) that receive and process alerts, choose materials and persons to engage with respect to the nature of calls, manage resources, and ensure communication with other services. Moreover, each SDIS possesses several Fire and Rescue Centres (CIS) responsible for engaging and sending resources chosen by the CTA to the intervention sites, communicating with intervention teams, and sending reinforcements if necessary. Similarly, each SAMU has several Call Reception and Dispatch Centres (CRRA) that receive calls, provide medical listening through medical regulators and prepare victims' admission in hospitalisation centres (Chehade et al., 2018). All these services and centres have to cooperate and communicate in order to accomplish their missions and duties on multiple organisational levels as shown in figure 2 .

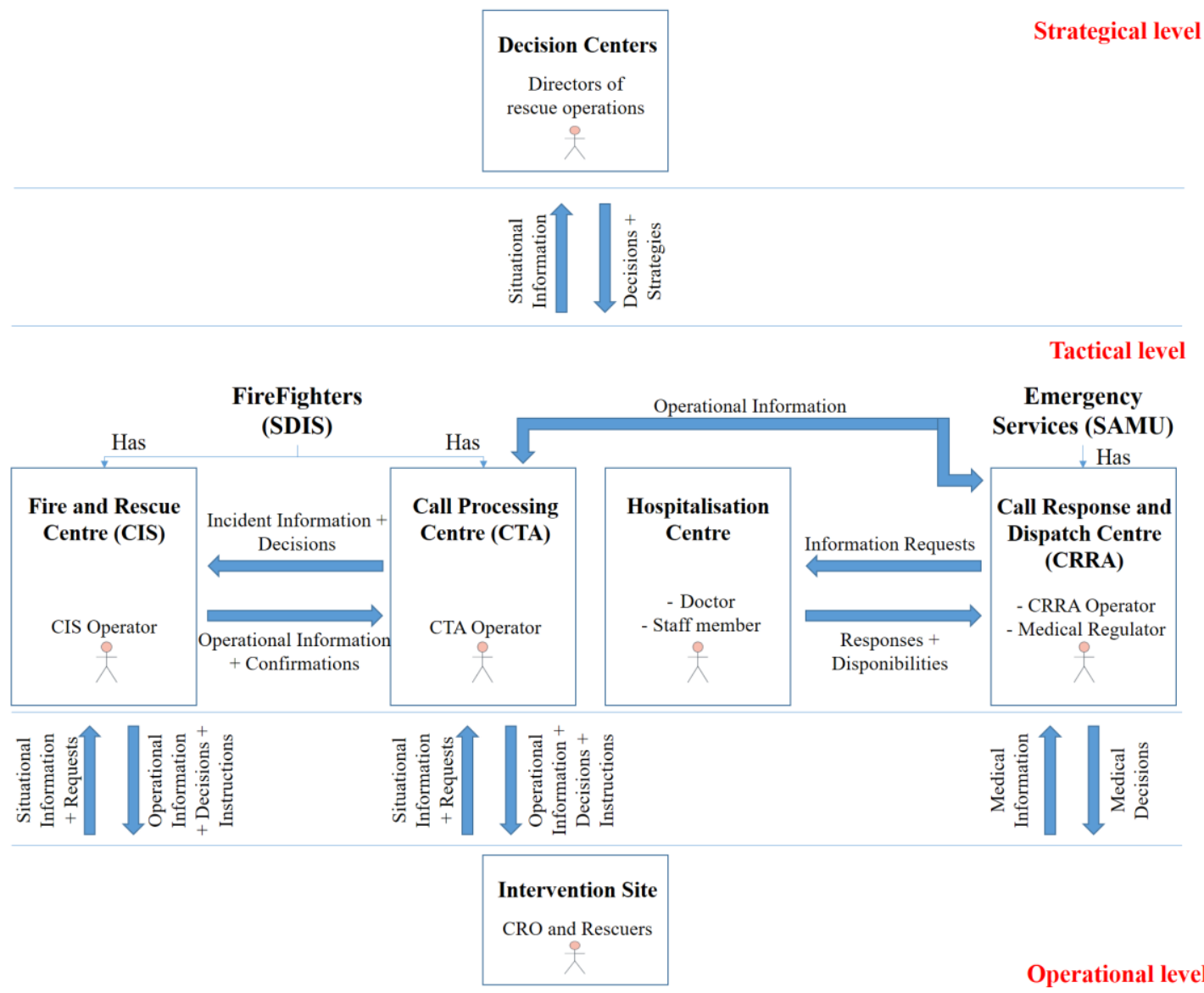

Figure 2: Organisational model and the general flow of information in French rescue operations 
Figure 2 shows a model that includes the organisational levels in French rescue operations, the composition of each level, and the general flow of information between these levels and within each level. As we can see in figure 2, in the French context, the hierarchical chain of command is composed of three main levels: The strategical level, the tactical level, and the operational level. The strategical level consists of public authorities' members that play the role of directors of rescue operations. Their main mission consists in fixing the strategy of the response. The tactical level consists of doctors and member staff in hospitalisation centres as well as operators and regulators in operational centres represented by: CTA Operators in Call Processing Centres (CTA) of FireFighters (SDIS); CIS Operators in Fire and Rescue Centres (CIS) of Firefighters (SDIS); And CRRA Operators and medical regulators in Call Response and Dispatch Centres (CRRA) of Emergency Medical Services (SAMU). Whereas, the operational level consists of the commander of rescue operations (CRO) and rescuers in the intervention site. The implication of the strategical level is limited to large-scale operations such as crisis management and large-events emergency responses. However, in the case of small scale rescue operations, which are the main interest of our work, most of the operations and communications take place at two levels only: The tactical and the operational level. Hence, we have focused our work on analysing and modelling communications and interactions between the tactical and the operational levels.

After having identified participating services in rescue operations, their missions, as well as their activities, let us move to the modelling phase. As a first step, one needs to identify modelling requirements and model components. Therefore, we request several requirements and we propose an interaction model.

\section{B. Requirements for modelling Interactions}

The principal purpose of our model is to represent interactions and information flow in rescue operations and then to provide a solution that aims at enhancing situation awareness. Related to awareness, reaching its highest level requires perceiving all factors of a situation within a volume of space and time as well as understanding their senses and relations. Furthermore, it is fundamental to determine each and every relevant information that informs on a situation as a first step toward supporting communications. Therefore, identifying situation elements and relevant information is the first step heading to improve situational awareness. These are the essential elements to take into account when modelling processes and interactions.

Ontologies can be greatly beneficial to characterise and represent the main elements of a situation as well as relationships between them (Chehade et al., 2019). The term Ontology was defined by Gruber as "an explicit specification of conceptualisation" (Gruber, 1993). Thus, we base our work on an ontology as an entry point for modelling and supporting awareness. Therefore, we take ResOnt ontology that was proposed in the work of (Chehade et al., 2019, 2018) as a fundamental source to identify the required elements. ResOnt ontology was created by adopting the three steps methodology proposed by (Bachimont et al., 2002). It follows the classification of the top-level ontology SUMO (Pease et al., 2002) and reuses classes from five existing ontologies: Emergel ontology (Azcona, 2013), the emergency response ontology (Li et al., 2008), EDXLRESCUER (Barros et al., 2015), the emergency ontology (Yu et al., 2008), and SAW ontology (Matheus et al., 2005). The main interest of ResOnt is to support situation awareness and communication in rescue operations by ensuring a common operational picture and shared situation understanding between different stakeholders. Moreover, it deals with all components, aspects, and factors in rescue operations such as actors, organisations, tasks, and materials. Figure 3 shows the classification of the core concepts defined in ResOnt that was implemented in Protégé software (Musen, 2015).

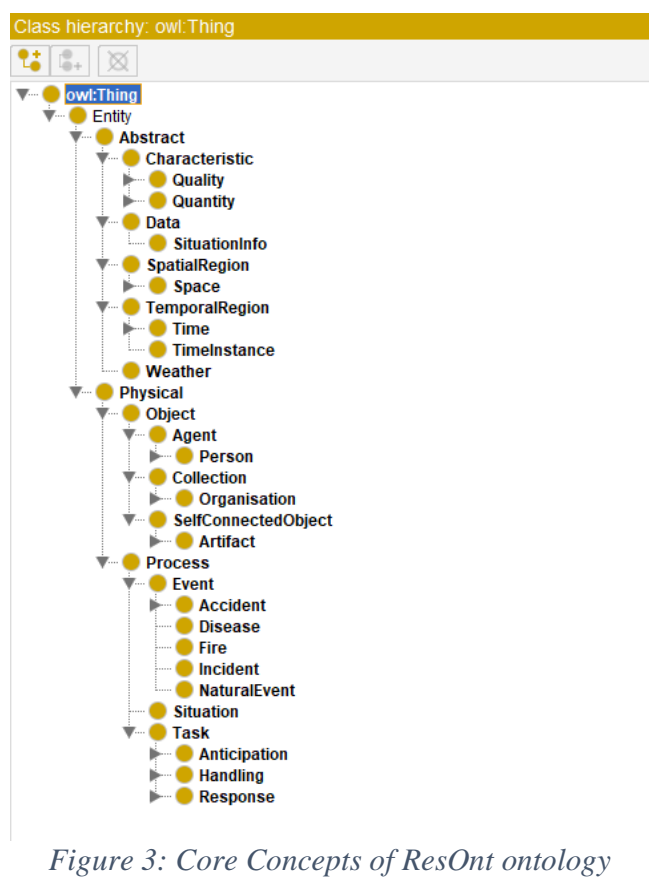


Another reason behind choosing ResOnt is that it takes communication and situation related information into consideration and those are important parameters for modelling interactions. Figure 4 represents a graph derived from the ontology showing some main concepts and relations between them.

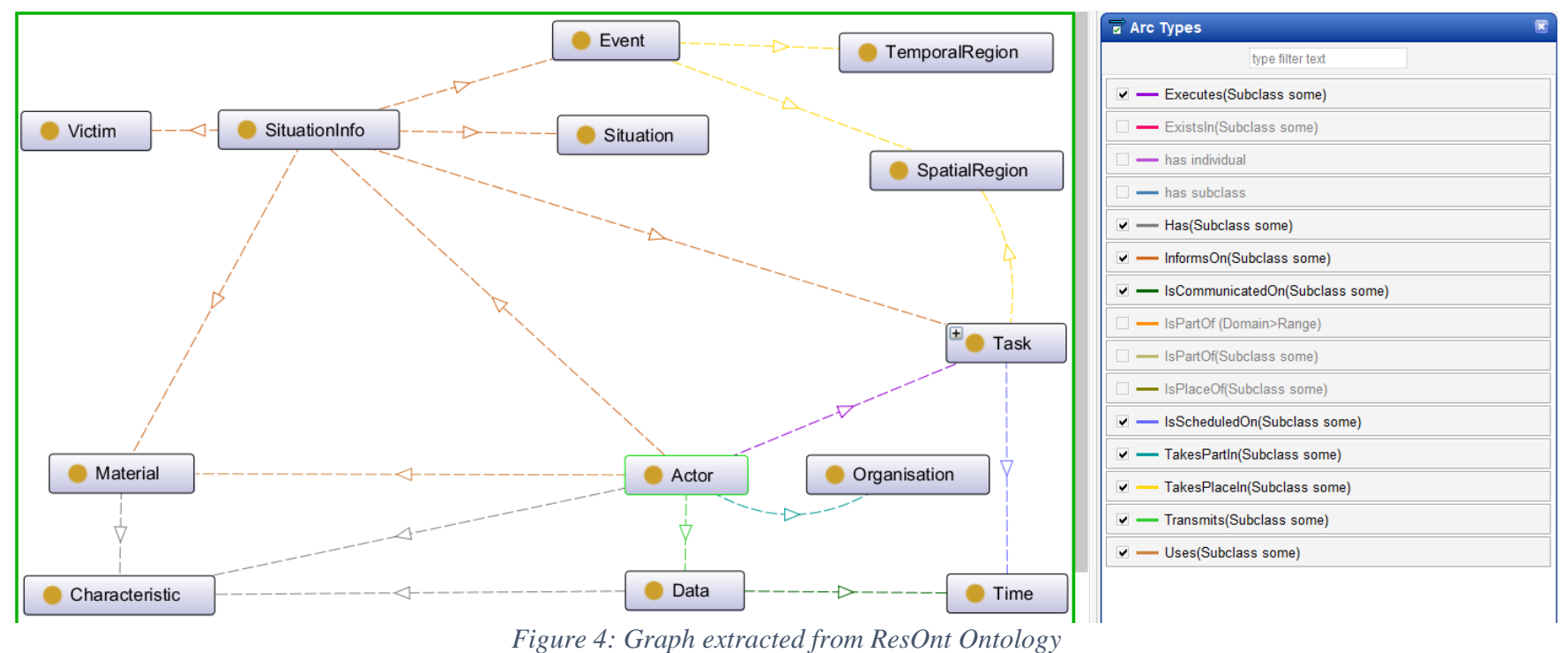

For example, an actor takes part in an organisation. Each actor has several characteristics represented by his role, skills, grade, and function. Depending on these characteristics, s/he executes specific tasks and actions that are scheduled on time and take place in different spatial regions. For that, s/he uses materials that have their own characteristics like availability and status. In order to achieve his/her tasks successfully, s/he exchanges data with other actors. This data is communicated on time and informs on situation related information, which is the main interest in our work. For instance, it can inform on victims, situation, task, material, and event that takes place in certain temporal and spatial regions.

Based on these concepts and relations, we identify the required elements to build up a comprehensive interaction model in rescue operations. The first element to take into account is Actors, their Roles, and their Positions in the organisational levels of operations. Any rescue operation requires the engagement of many persons who can play distinct roles according to their functions, skills, and position in the organisational levels. Therefore, making the difference between various actors and organisational levels of operations is important for modelling. The second element to consider is the tasks and actions executed. Every actor has to accomplish different actions in order to fulfil his responsibilities. Some actions are of responsibility of single actors and may produce or require situation related information while other actions need the interaction and collaboration of multiple actors and generate an information flow between them. Hence, it is also important to consider them since most of the interactions are based on these actions. In our model, we refer to actions and activities by Operations and Tasks. Another primary element is Data or Information. This is the foundation of interactions and situation awareness. It instructs on situations and all the perceived elements in an environment. In this context, specifying which information is being shared or consulted at each step is vital in modelling interactions. In addition, exchanging and consulting this information require using appropriate communication tools. Consequently, it is also crucial to identify the Device that enables communication together with the type of communication. Furthermore, actors involved in rescue operations are geographically separated. Some of them are present in intervention sites like first responders, while others stay in dispatch or rescue centres. As already explained, operations, tasks, and communications take place at different locations. It is thereby required to distinguish between distinct Locations when modelling. Finally, it is of the highest importance to consider Time parameter since rescue operations are dynamic and evolve continuously with time evolution. This dynamic aspect alters the state of other situation elements such as tasks and situation information. However, modelling complex processes, such as rescue operations, while taking into account time parameter is explicitly challenging. (Nunavath \& Prinz, 2015) state that modelling complex and dynamic activities requires splitting those processes into many phases and separating them with respect to time. Therefore, we split a rescue operation into several main phases including each many sub-phases and we illustrate their chronology on a timeline as shown in figure 5 . As we can see in this figure, a rescue operation can be split into six principal phases: alert, involvement of persons and resources, departure to the incident site, on-site operations, victims' transportation, and finally, return to rescue centres. From all of the above, we can summarise elements to take into account when modelling interactions by: Actors, their Roles and their Positions in the organisational levels of operations, Information or Data, Communication device, Tasks and Operations, Time, and Location. 


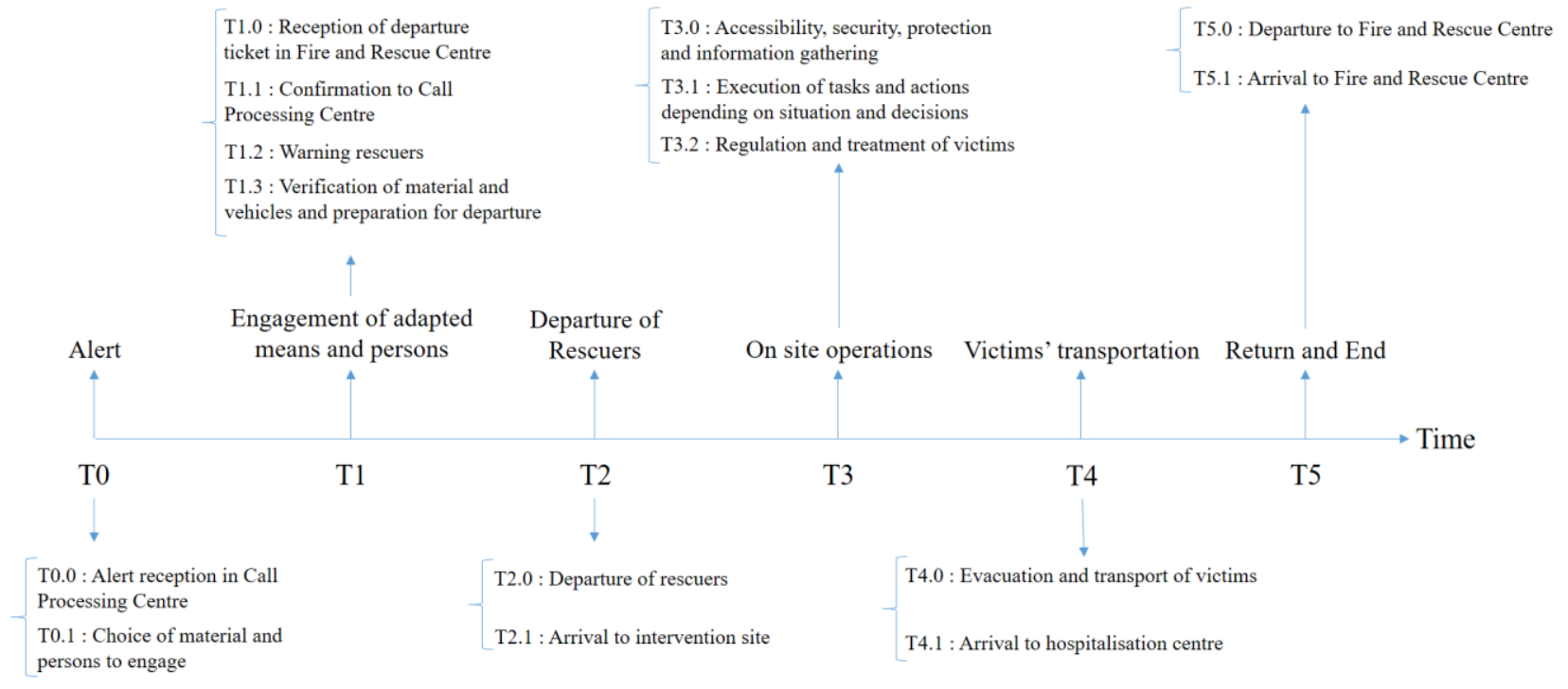

Figure 5: Chronology of phases in rescue operations

\section{Interaction Model}

There exist several approaches and techniques to represent and formalise processes, activities, and interactions. Some techniques are based on business process models and diagrams while others are derived from multi-agent approaches. In this paper, we choose to adopt the approach that is based on business process modelling by using UML diagrams due to many reasons. The first reason is that process models and diagrams can be used to model dynamic processes, interactions, and sequences by taking several parameters into consideration. The second reason is that business process models enable the representation of information flow between different actors, which is important for modelling interactions. Eventually, the third reason is that process models and UML Diagrams are clear and easy to understand by domain experts. However, none of the existing UML diagrams allows representing interactions in a single model with taking into consideration all the previously defined parameters. To this end, we do a mixture of UML Collaboration Diagram, UML Activity Diagram, and UML Sequence Diagram (Glassey, 2008) to represent our model clearly in one diagram as shown in the illustrative example in figure 6.

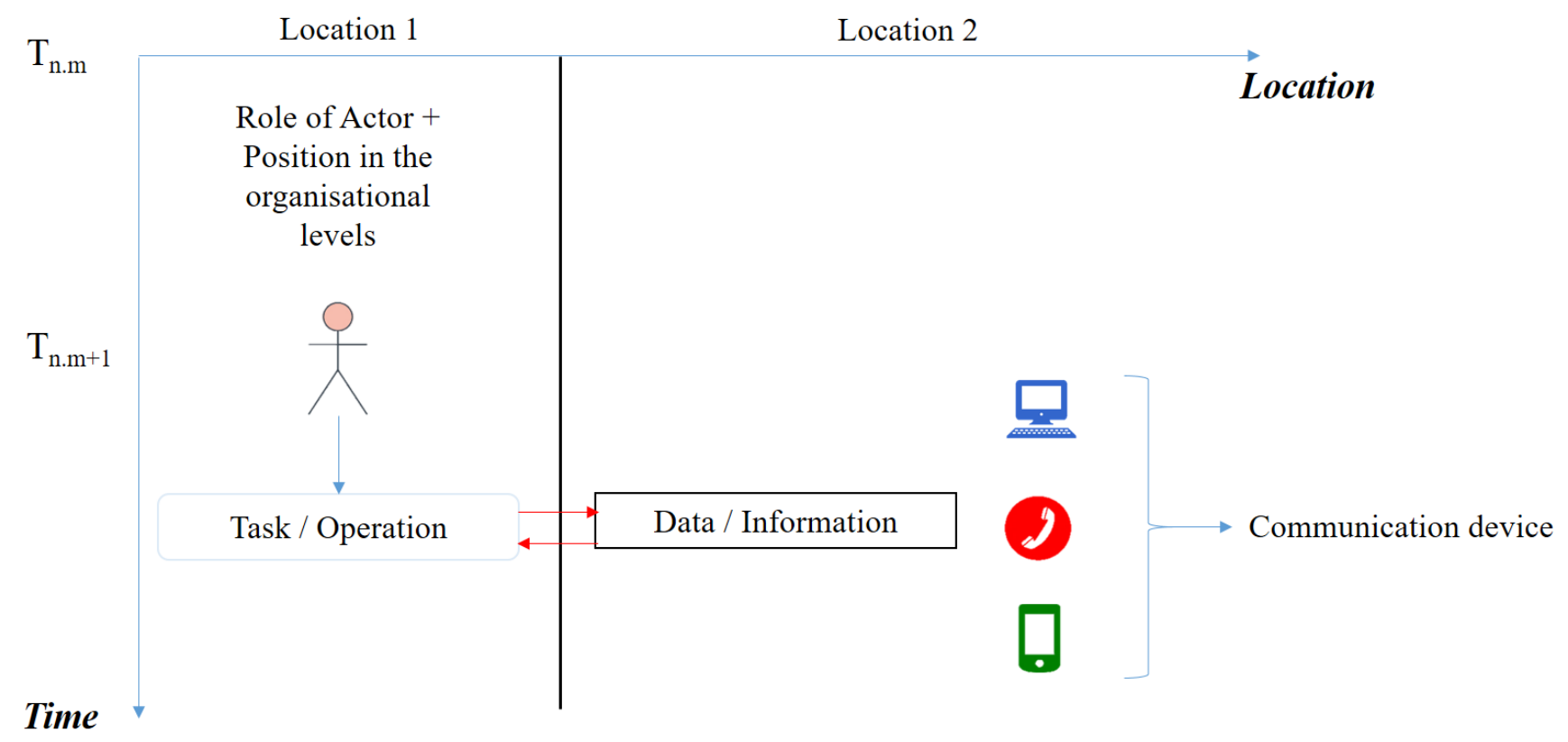

Figure 6: Interactions structure model

In this figure 6, the proposed structure model is based on two axes, a vertical one representing time and a horizontal one representing locations. On the time axis, we can see the sequence of activities and actions with respect to time. Moreover, it allows the separation between different phases and sub-phases of an operation. These subphases are separated through different timestamps. While on the location axis, we can separate between different places in which an action occurs or an information 
is being shared or consulted. To this end, locations are separated horizontally through different columns. Furthermore, this model includes actors and their roles together with their position in the organisational levels of operations represented by an icon of a dummy person. This actor can execute a task represented by rectangles with rounded corners. To do that, s/he needs access to some information. In addition, any task can generate information to be exchanged with other actors. Information is represented by rectangles in the model. Moreover, the proposed model also includes the communication device used to exchange or visualise information. Indeed, three types of devices are used in rescue operations so that information is transmitted and received through three possible ways: Non-oral communication via Mobile phones represented by green mobile phone icons; Non-oral communication via desktops represented by blue desktop icons; And oral communication through radio devices and handsets represented by red circle icons. We notice that the proposed structure model aims only at representing the main parameters to take into consideration when modelling interactions. In addition, it is a general model that serves as a reference to illustrate the interactions through an interaction model and does not represent any specific case in rescue operations where several activities may run in parallel.

After creating the structure model, we move to the last step, which is building up an interaction model for rescue operations. To this end, we adopt an approach based on French procedures and practices. We consider an incident causing one or many casualties and requiring the involvement of several actors from different services. Armed with their equipment and vehicles, intervention teams, composed of rescuers and Commander of Rescue Operations (CRO), access incident sites. They secure places, protect casualties, gather information and exchange it with operators, execute adequate actions, and finally transfer victims to a hospitalisation centre. In figure 7, we show a portion of the interactions model illustrated on the structure model. It represents actions, communications, and interactions during the on-site operations phase that begins at T3. Unfortunately, because of space limitations, we only present the firsts two sub-phases of on-site operations. We notice that in figure 7, blue arrows represent the sequence of tasks. Red arrows are used to show the relation between the tasks and the produced or required information if any. While black arrows are used to show the information flow between actors and thus between the organisational levels of operations. Moreover, in this figure, we highlight tasks that need the interaction and collaboration of multiple actors by underlining them.

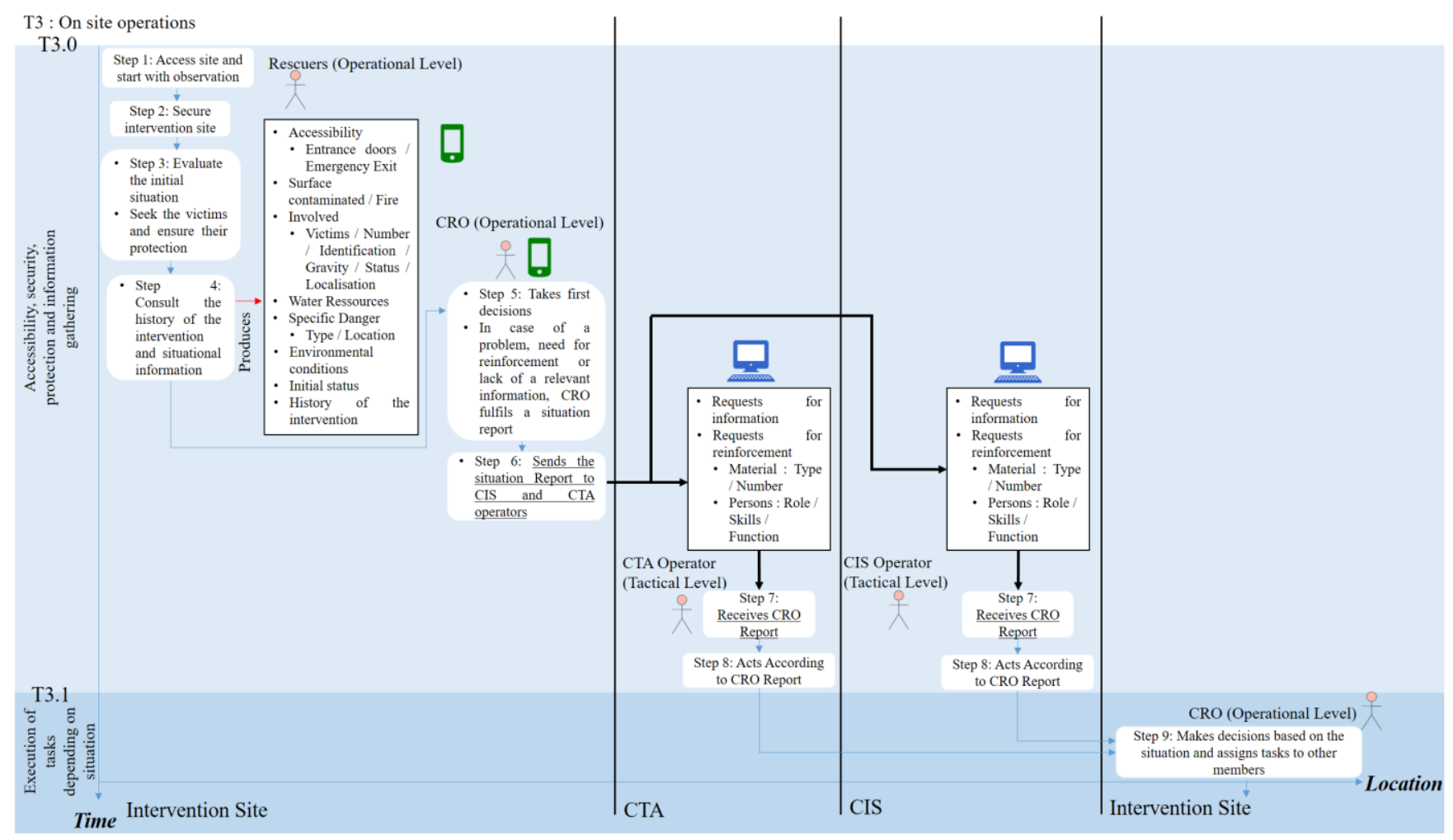

Figure 7: Interactions during on-site operations

At T3.0, and after leaving their CIS, rescuers access the intervention site. They start by securing places, evaluating the initial situation, and searching casualties for protecting them. The first three steps in figure 7 represent these three tasks. Then, they gather first information about the incident and consult the history of the intervention to evaluate the real situation and act appropriately. Hence, they will have access to information related to accessibility, contaminated surface, involved victims, resources and environmental conditions, as well as the history of the intervention. This task is represented by step 4 in figure 7. Based on this information, the CRO takes his first decisions at the operational level. In case of any problem, lack of information, or need for reinforcements, operators in CTA and CIS must be notified. Hence, the CRO fulfils a situation report 
through a mobile phone and shares it with CIS and CTA operators who exist in CIS and CTA respectively at the tactical level. Those operators will thus receive and check the CRO report through their desktops and act according to it. Steps 5, 6, 7, and 8 in figure 7 represent these tasks respectively. At T3.1, rescuers finish the first sub-phase consisting of accessibility, security, protection and information gathering, and a new sub-phase begins. The CRO, who exists in the intervention site at the operational level, makes new decisions and assigns tasks to other rescuers who start to carry out actions and operations based on the situation. This task is represented by step 9 in figure 7. From this figure, we can see how involved actors interact with each other depending on the actions and the situation. Moreover, we can see the needed or produced information in each step together with the device used to exchange it. From the model presented in figure 7, we can easily extract dependencies between Actor, Action, Information, Communication device, Operation phase, Location, and Time. In addition, we can simply see the information flow between the operational level and tactical level in rescue operations. Moreover, this model serves as a basis to define the communication requirements based on communication protocols defined in rescue operations and thus, to support the representation of situations. However, it does not cover all of the uncertainties that may occur in terms of activities and information since most of these uncertainties cannot be predicted in the aforementioned protocols.

\section{REQUIREMENTS FOR EFFECTIVE COMMUNICATION}

After having modelled interactions and communications, we move to the next step and we propose communication requirements that must be integrated in Rescue MODES for use by all actors involved in rescue operations. Those requirements should be respected in any system designed to be used by operational units. The importance of this step is that it serves as a basis in order to define specifications, architecture, and functionalities of the system to design. In addition, we present several existing communication systems used by French actors, and we show how each system meets these requirements based on their specifications. The reason behind focusing on French systems is that our model is based on French practices, which are slightly different in other countries due to differences in organisation, services, and actors.

The definition of requirements is based on the obtained interaction model. To this end, it is proposed to take each element and parameter from the interaction model and to define requirements with respect to each parameter. The first set of requirements is based on the location parameter and consists in ensuring the communication between different locations. Based on the French practices, several actors belonging to different centres are involved in a rescue operation. These actors are geographically distributed and allocated to a location of the following types: intervention sites, hospitalisation centres, CTA, CIS, and CRRA. It is therefore necessary to ensure communication between actors regardless their location. Hence, we define five requirements with regard to different locations as presented in table 1. As we can see in this table, none of the presented systems meets all those requirements. Most of them focus on communications between intervention sites and CRRA for medical regulation purposes while communications between several locations within the same intervention site are not supported in any case.

\begin{tabular}{|c|c|c|c|c|c|c|c|c|c|c|}
\hline Locations & 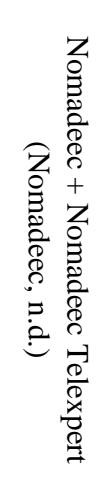 & 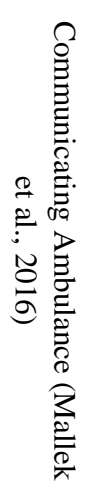 & 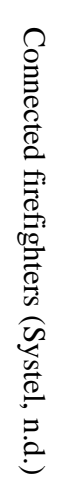 & 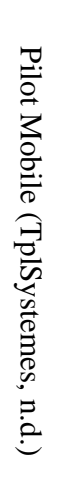 & 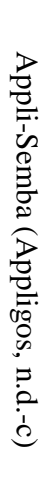 & 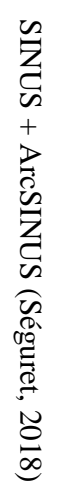 & 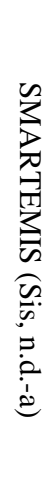 & 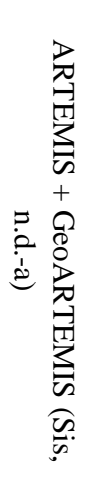 & 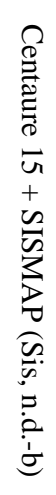 & 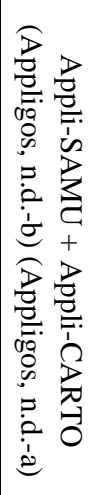 \\
\hline Between CIS and CTA & & & $\mathrm{X}$ & & & & & $\mathrm{X}$ & & \\
\hline $\begin{array}{l}\text { Between intervention sites and } \\
\text { CIS/CTA }\end{array}$ & & & $\mathrm{X}$ & $\mathrm{X}$ & & & $\mathrm{X}$ & $\mathrm{X}$ & & \\
\hline \multicolumn{11}{|l|}{$\begin{array}{l}\text { Between several locations within } \\
\text { the same intervention site }\end{array}$} \\
\hline $\begin{array}{l}\text { Between intervention sites and } \\
\text { CRRA }\end{array}$ & $\mathrm{X}$ & $\mathrm{X}$ & & & $\mathrm{X}$ & $\mathrm{X}$ & & & $\mathrm{X}$ & $X$ \\
\hline $\begin{array}{l}\text { Between intervention sites and } \\
\text { hospitalisation centres }\end{array}$ & $\mathrm{X}$ & & & & & $\mathrm{X}$ & & & & \\
\hline
\end{tabular}

Table 1: Systems classification and requirements according to location parameter

Some other identified requirements are related to communication type and supporting device. As discussed previously, it is assumed that several types of communication are supposed to occur between actors in rescue operations such as oral and non- 
oral communication. Hence, the system should support any type of communication by providing the required communication device as shown in table 2. For instance, it must allow intervention teams to use mobile phones in order to exchange information with rescue centres. Unfortunately, table 2 shows that only one out of the ten presented systems supports the three communication types together.

\begin{tabular}{|c|c|c|c|c|c|c|c|c|c|c|}
\hline Communication type & 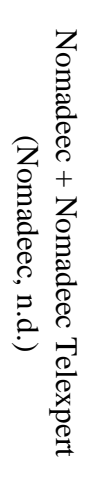 & 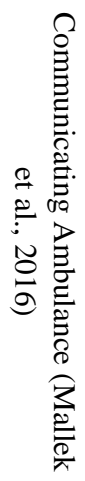 & 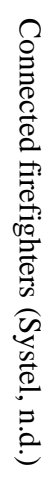 & 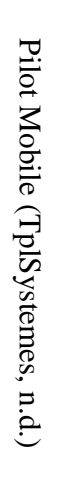 & 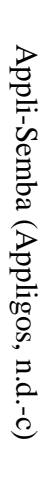 & 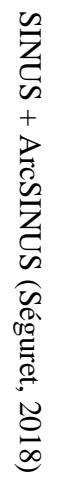 & 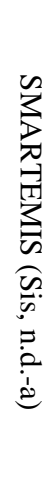 & 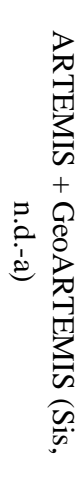 & 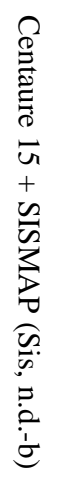 & 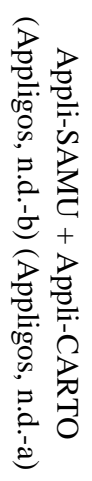 \\
\hline $\begin{array}{l}\text { Oral communication via radio, } \\
\text { mobile phones and landlines }\end{array}$ & $\mathrm{X}$ & & & $\mathrm{X}$ & & & & & & \\
\hline $\begin{array}{l}\text { Non-oral communication via } \\
\text { mobile devices, and PDAs }\end{array}$ & $\mathrm{X}$ & $\mathrm{X}$ & $\mathrm{X}$ & $\mathrm{X}$ & $\mathrm{X}$ & & $\mathrm{X}$ & & & \\
\hline $\begin{array}{l}\text { Non-oral communication via } \\
\text { desktops }\end{array}$ & $\mathrm{X}$ & $\mathrm{X}$ & $\mathrm{X}$ & & & $\mathrm{X}$ & & $\mathrm{X}$ & $\mathrm{X}$ & $\mathrm{X}$ \\
\hline
\end{tabular}

Table 2: Systems classification and requirements related to communication type

Furthermore, we define requirements with respect to actors' parameters. Since multiple actors from different services are involved in rescue operations, it is mandatory to allow each of them to use the system and to communicate with other actors. In this context, we identify requirements based on actors' roles as we can see in table 3 . In this table, we can see that actors with a total of eight different roles participate in rescue operations. However, in our best knowledge, none of the existing systems considers more than five roles.

\begin{tabular}{|c|c|c|c|c|c|c|c|c|c|c|}
\hline Actors' roles & 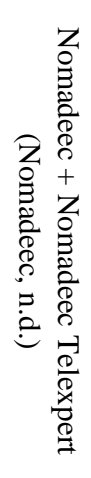 & 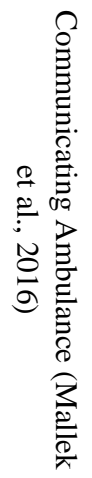 & 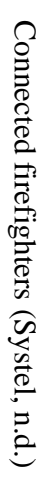 & 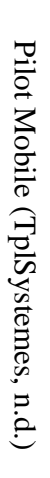 & 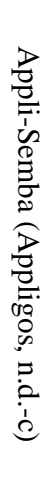 & 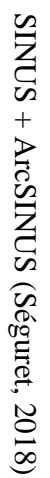 & 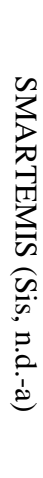 & 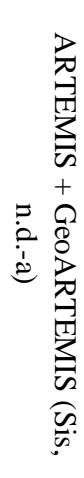 & 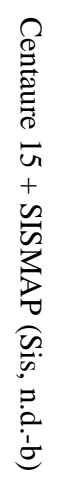 & 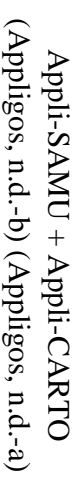 \\
\hline Driver & & & & $\mathrm{X}$ & & & $\mathrm{X}$ & & & \\
\hline $\begin{array}{l}\text { On-site commander of rescue } \\
\text { operations }\end{array}$ & $\mathrm{X}$ & $\mathrm{X}$ & $\mathrm{X}$ & $\mathrm{X}$ & $\mathrm{X}$ & $\mathrm{X}$ & $\mathrm{X}$ & & & \\
\hline Rescuers on intervention sites & $\mathrm{X}$ & $\mathrm{X}$ & $\mathrm{X}$ & $\mathrm{X}$ & $\mathrm{X}$ & $\mathrm{X}$ & $\mathrm{X}$ & & & \\
\hline Operator in CTA & & & $\mathrm{X}$ & & & & $\mathrm{X}$ & $\mathrm{X}$ & & \\
\hline Operator in CIS & & & $\mathrm{X}$ & & & & $\mathrm{X}$ & $\mathrm{X}$ & & \\
\hline Operator in CRRA & $\mathrm{X}$ & $\mathrm{X}$ & & & & $\mathrm{X}$ & & & $\mathrm{X}$ & $\mathrm{X}$ \\
\hline Medical regulator in CRRA & $\mathrm{X}$ & $\mathrm{X}$ & & & & $\mathrm{X}$ & & & $\mathrm{X}$ & $\mathrm{X}$ \\
\hline Doctor in hospitalisation centres & $\mathrm{X}$ & & & & & $\mathrm{X}$ & & & & \\
\hline
\end{tabular}

Table 3: Systems classification and requirements according to actors' roles

Moreover, participating actors have different roles with distinct grades and functions. These differences in roles result in differences in communication needs and permissions. For example, the conductor is not allowed to access medical information of victims while a regulator does not need to obtain operational information such as information about resources. It is therefore necessary to restrict communications and system functionalities according to actors' roles and grades. In this manner, it is 
essential beyond the communication features to consider the information system access management. Surprisingly, most of the studied systems do not include authorisation management features as shown in table 4.

\begin{tabular}{|c|c|c|c|c|c|c|c|c|c|c|}
\hline Mechanism & 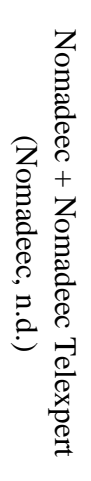 & 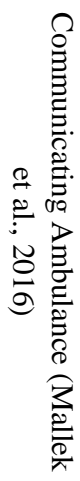 & 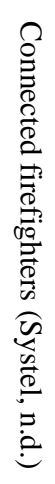 & 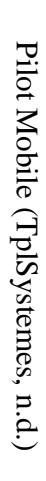 & 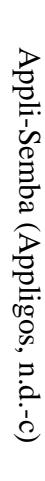 & 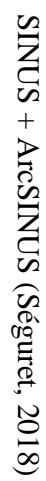 & 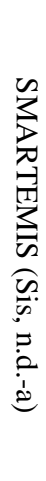 & 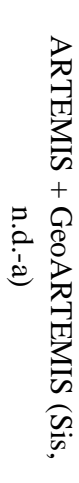 & 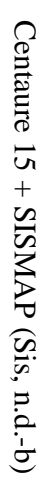 & 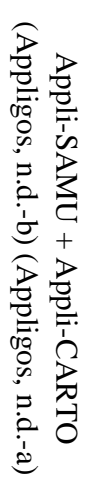 \\
\hline Role-based access management & $\mathrm{X}$ & & & & & $\mathrm{X}$ & & & & \\
\hline Grade-based access management & & & & & & & $\mathrm{X}$ & & & \\
\hline
\end{tabular}

Table 4: Systems classification and requirement related to authorisation management

Another important parameter to consider during communications is the information itself. Consequently, we defined several requirements with respect to this parameter. As it has been illustrated in the interaction model, rescue operations require the communication of different forms of data such as operational information on resources and cartography, as well as medical information like number and seriousness of victims along with their records. Hence, it is fundamental to allow the communication of different types of data. Thus, and in agreement with the rescue interaction model, we define different requirements based on the data type as presented in table 5. Unfortunately, this table shows that some data types are not supported in any of the studied systems such as information on specific dangers, requests for reinforcements, and environmental conditions. Moreover, table 5 shows that many of the communication systems studied does not take into account most of the data types that need to be communicated.

\begin{tabular}{|c|c|c|c|c|c|c|c|c|c|c|}
\hline Type of Data & 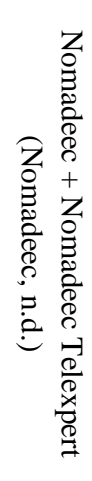 & 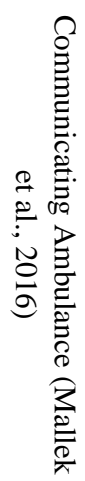 & 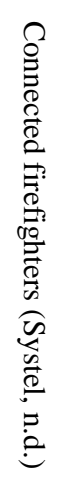 & 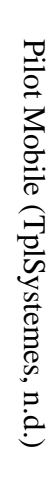 & 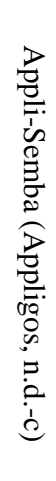 & 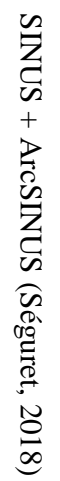 & 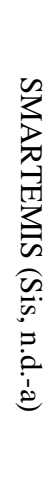 & 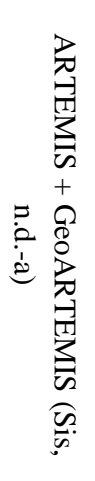 & 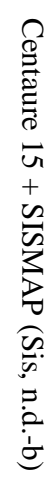 & 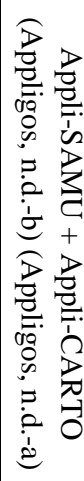 \\
\hline Incident type and time & & & $\mathrm{X}$ & $\mathrm{X}$ & & & $\mathrm{X}$ & $\mathrm{X}$ & $\mathrm{X}$ & $\mathrm{X}$ \\
\hline $\begin{array}{l}\text { Intervention site: Address, } \\
\text { Accessibility, Type }\end{array}$ & & & $\mathrm{X}$ & $\mathrm{X}$ & & & $\mathrm{X}$ & $\mathrm{X}$ & $\mathrm{X}$ & $\mathrm{X}$ \\
\hline $\begin{array}{l}\text { General information about } \\
\text { victims: Number, identification, } \\
\text { gravity, status }\end{array}$ & $\mathrm{X}$ & $\mathrm{X}$ & $\mathrm{X}$ & $\mathrm{X}$ & $\mathrm{X}$ & $\mathrm{X}$ & & $\mathrm{X}$ & $\mathrm{X}$ & $\mathrm{X}$ \\
\hline \multicolumn{11}{|l|}{ Specific dangers: Type, locations } \\
\hline Centres' cartography & & & $\mathrm{X}$ & & & & & $\mathrm{X}$ & & \\
\hline Material cartography & & & $\mathrm{X}$ & & & & $\mathrm{X}$ & $\mathrm{X}$ & $\mathrm{X}$ & $\mathrm{X}$ \\
\hline Persons' cartography & & & $\mathrm{X}$ & & & & $\mathrm{X}$ & $\mathrm{X}$ & $\mathrm{X}$ & $\mathrm{X}$ \\
\hline $\begin{array}{l}\text { Material to engage: Type, } \\
\text { number }\end{array}$ & & & $\mathrm{X}$ & & & & & $\mathrm{X}$ & $\mathrm{X}$ & $\mathrm{X}$ \\
\hline $\begin{array}{l}\text { Actors to engage: Identification, } \\
\text { role, skills, function }\end{array}$ & & & $\mathrm{X}$ & & & & & $\mathrm{X}$ & $\mathrm{X}$ & $\mathrm{X}$ \\
\hline $\begin{array}{l}\text { Problems related to unavailability } \\
\text { and failures }\end{array}$ & & & & & & & & & & \\
\hline
\end{tabular}




\begin{tabular}{|c|c|c|c|c|c|c|c|c|c|c|}
\hline $\begin{array}{l}\text { Engaged material and persons } \\
\text { and their locations }\end{array}$ & & & $\mathrm{X}$ & $\mathrm{X}$ & & & $\mathrm{X}$ & $X$ & $\mathrm{X}$ & $\mathrm{X}$ \\
\hline $\begin{array}{l}\text { Date and time of intervention, } \\
\text { departure and return of the } \\
\text { rescuers }\end{array}$ & & & $\mathrm{X}$ & $\mathrm{X}$ & & & & & $\mathrm{X}$ & $\mathrm{X}$ \\
\hline Procedural guides & & $\mathrm{X}$ & $\mathrm{X}$ & $\mathrm{X}$ & $\mathrm{X}$ & & & & & \\
\hline $\begin{array}{l}\text { Interest points (Water resources, } \\
\text { hospitals...) and their locations }\end{array}$ & & & & & & & & $\mathrm{X}$ & & \\
\hline \multicolumn{11}{|l|}{ Contaminated surface } \\
\hline \multicolumn{11}{|l|}{ Environmental conditions } \\
\hline $\begin{array}{l}\text { Evolution of the situation and } \\
\text { occurrence of events }\end{array}$ & $\mathrm{X}$ & $\mathrm{X}$ & $\mathrm{X}$ & $\mathrm{X}$ & & $\mathrm{X}$ & & & & \\
\hline History of the intervention & & & & & & & $\mathrm{X}$ & & & \\
\hline $\begin{array}{l}\text { Requests for reinforcements: } \\
\text { Materials, persons }\end{array}$ & & & & & & & & & $\mathrm{X}$ & \\
\hline Actions executed & $\mathrm{X}$ & $\mathrm{X}$ & $\mathrm{X}$ & $\mathrm{X}$ & & $\mathrm{X}$ & & & $\mathrm{X}$ & \\
\hline Decisions (Tasks to do) & & $\mathrm{X}$ & & & & & & & & $\mathrm{X}$ \\
\hline Medical record & $\mathrm{X}$ & $\mathrm{X}$ & $\mathrm{X}$ & $\mathrm{X}$ & $\mathrm{X}$ & $\mathrm{X}$ & & & $\mathrm{X}$ & $\mathrm{X}$ \\
\hline $\begin{array}{l}\text { Vital parameters (real time } \\
\text { medical data) }\end{array}$ & $\mathrm{X}$ & $\mathrm{X}$ & & $\mathrm{X}$ & & & & & & \\
\hline Medical history of the victim & $\mathrm{X}$ & & & & & & & & $\mathrm{X}$ & \\
\hline $\begin{array}{l}\text { Hospitalisation centres: } \\
\text { Locations, disponibility }\end{array}$ & & $\mathrm{X}$ & & & $\mathrm{X}$ & & & & $\mathrm{X}$ & $\mathrm{X}$ \\
\hline Intervention reports & $\mathrm{X}$ & & $\mathrm{X}$ & $\mathrm{X}$ & & & & & & \\
\hline
\end{tabular}

The different pieces of information identified previously can be of various forms, which leads to other essential requirements. For example, rescuers might share photos or videos from the scenes to share a clear operational picture. Moreover, they may send voice messages to simplify their tasks by avoiding typing. Thus, actors should have the ability to exchange different forms of data through the system as shown in table 6. As we can see in this table, all of the existing systems support the communication of information in form of text. However, other forms of data such as photos and videos are barely supported.

\begin{tabular}{|c|c|c|c|c|c|c|c|c|c|c|}
\hline Form of data & 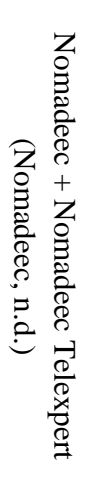 & 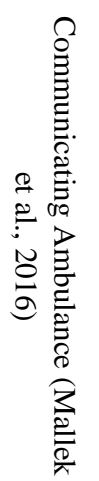 & 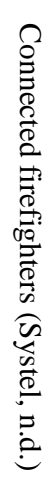 & 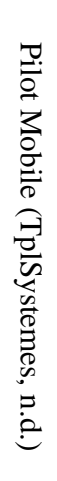 & 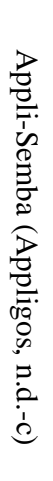 & 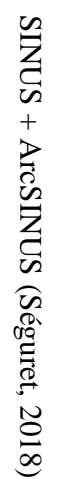 & 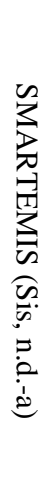 & 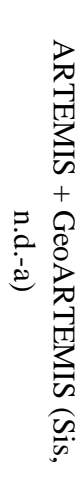 & 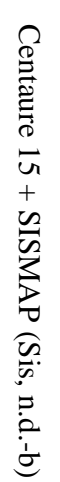 & 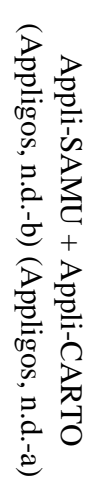 \\
\hline Text & $\mathrm{X}$ & $X$ & $\mathrm{X}$ & $\mathrm{X}$ & $X$ & $\mathrm{X}$ & $\mathrm{X}$ & $\mathrm{X}$ & $\mathrm{X}$ & $\mathrm{X}$ \\
\hline Photo & $\mathrm{X}$ & & & & & & & & & \\
\hline Audio & $\mathrm{X}$ & & & $\mathrm{X}$ & & & & & & \\
\hline Video & $\mathrm{X}$ & & & & & & & & & \\
\hline $\begin{array}{l}\text { Signals (Electrocardiogram; } \\
\text { Sensors) }\end{array}$ & $\mathrm{X}$ & $\mathrm{X}$ & & $X$ & & & & & & \\
\hline
\end{tabular}

Table 6: Systems classification and requirements according to supported forms of data

Moreover, since rescue operations require the exchange of personal and medical information, it is fundamental to ensure the security of those communications. In other words, it is mandatory to guarantee the confidentiality, the reliability, and the integrity of exchanged information. For that reason, several techniques must be implemented such as the anonymization and encryption of data, data versioning, as well as users' authentication to prevent forbidden access. Table 7 shows the identified requirements related to data security and reliability. In this table, we can see that five out of ten systems do not integrate any of those techniques. Furthermore, none of the studied systems includes data versioning technique that is important for guarantying the integrity of exchanged information. 


\begin{tabular}{|c|c|c|c|c|c|c|c|c|c|c|}
\hline Mechanism & 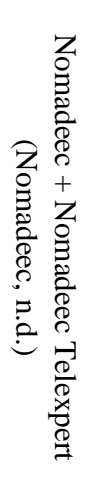 & 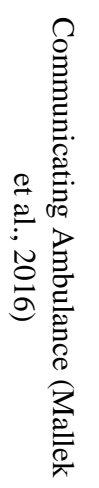 & 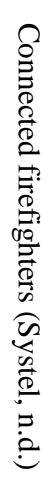 & 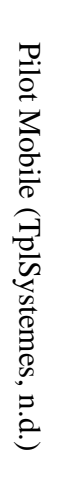 & 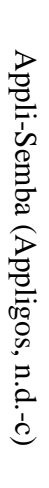 & 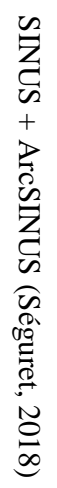 & 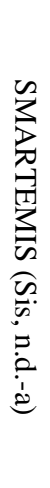 & 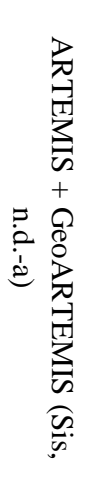 & 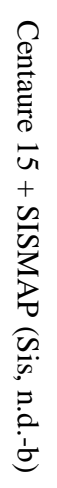 & 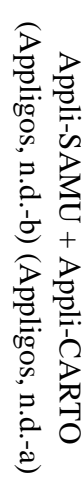 \\
\hline $\begin{array}{l}\text { Guarantying secured exchange } \\
\text { of information (anonymization, } \\
\text { encryption of data...) }\end{array}$ & $\mathrm{X}$ & & & & & $\mathrm{X}$ & & $\mathrm{X}$ & $\mathrm{X}$ & \\
\hline $\begin{array}{l}\text { Securing access to the system by } \\
\text { authentifying users }\end{array}$ & $\mathrm{X}$ & & & & & $\mathrm{X}$ & $\mathrm{X}$ & $\mathrm{X}$ & $\mathrm{X}$ & \\
\hline Data versioning & & & & & & & & & & \\
\hline
\end{tabular}

Eventually, with relation to time parameter, a vital need is allowing the communication during all phases of the intervention. Thus, the system should be designed in a way to serve actors from the beginning of an operation, during the emergency call, until its end and the return of intervention teams without the need to use another system. Different requirements related to this need are summarised in table 8. Those requirements are derived from the six main phases of an operation. As we can see in this table, only three out of ten systems support communications during all phases of an operation while other systems focus on communications during on-site operations and victims' transportation phases.

\begin{tabular}{|c|c|c|c|c|c|c|c|c|c|c|}
\hline System & 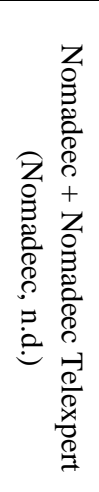 & 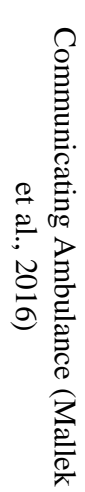 & 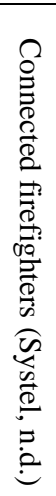 & 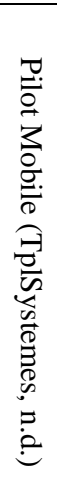 & 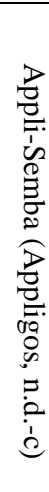 & 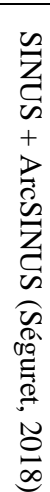 & 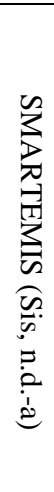 & 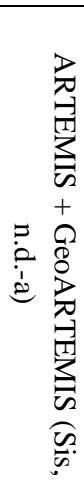 & 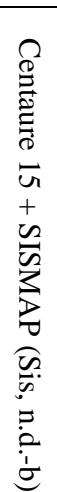 & 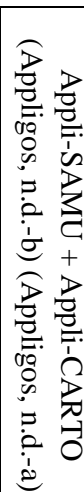 \\
\hline Alert & & & $\mathrm{X}$ & & & & $\mathrm{X}$ & $\mathrm{X}$ & $\mathrm{X}$ & $\mathrm{X}$ \\
\hline $\begin{array}{l}\text { Engagement of adapted means } \\
\text { and persons }\end{array}$ & & & $\mathrm{X}$ & $\mathrm{X}$ & & & & $\mathrm{X}$ & $\mathrm{X}$ & $\mathrm{X}$ \\
\hline Departure of rescuers & & & $\mathrm{X}$ & $\mathrm{X}$ & & & $\mathrm{X}$ & $\mathrm{X}$ & $\mathrm{X}$ & $\mathrm{X}$ \\
\hline On-site operations & $\mathrm{X}$ & $\mathrm{X}$ & $\mathrm{X}$ & $\mathrm{X}$ & $\mathrm{X}$ & $\mathrm{X}$ & $\mathrm{X}$ & $\mathrm{X}$ & $\mathrm{X}$ & $\mathrm{X}$ \\
\hline Victims' transportation & $\mathrm{X}$ & $\mathrm{X}$ & $\mathrm{X}$ & $\mathrm{X}$ & $\mathrm{X}$ & $\mathrm{X}$ & $\mathrm{X}$ & $\mathrm{X}$ & $\mathrm{X}$ & $\mathrm{X}$ \\
\hline Return & & & $\mathrm{X}$ & $\mathrm{X}$ & & & $\mathrm{X}$ & $\mathrm{X}$ & $\mathrm{X}$ & \\
\hline
\end{tabular}

Table 8: Systems classification and requirements according to time parameter

As cited in the related work and as it has been shown in this section, several communication systems already exist and are used by emergency actors inside and outside France. Unfortunately, none of those systems has succeeded in responding to all requirements. For instance, some of them focus on medical information while others give high priority to operational information. In addition, most of the existing systems are oriented for specific emergency services without considering other involved services. For example, some systems are oriented for firefighters while others are oriented for medical services. Moreover, almost all of the existing systems are commercial systems owned by different companies. A direct result of this situation is that the information is heterogeneous; they are stored in distinct data sources with distinct forms and semantics. This heterogeneity results in a deficiency of interoperability between the existing systems (Elmhadhbi et al., 2018). Therefore, it is almost impossible to combine the existing systems into one interoperable system that responds to all of the identified 
requirements. Based on the aforementioned reasons, a real need for implementing a new system that fulfils all the requirements was identified. Therefore, we introduced Rescue MODES, a system we aim to implement in order to support communications and situational awareness and that, in our beliefs, will meet all communication requirements. To this end, we modelled interactions with respect to activities based on a deep study of domain-related documentation. We also identified required elements to consider when modelling interactions in rescue operations and we used those requirements to design a structure model. Moreover, we applied the structure model to a rescue operation example in France and we proposed an interaction model. Finally, we defined communication requirements based on the obtained model as a mandatory step before defining the architecture and specifications of the system. Those requirements can serve as a basis for any other communication system to be implemented in rescue and emergency response domains.

\section{CONCLUSION}

This work aimed to introduce Rescue MODES, a communication and information exchange system oriented to support situation awareness amongst French emergency actors in rescue operations. At first, communications and interactions in rescue operations were examined by studying practices based on domain-related documents and laws. After that, these interactions were modelled based on several mandatory elements, which were defined on the basis of an application ontology. These elements are location, time, actors and their roles, tasks, information, and communication device. The motivation behind using an ontology is two-folded; it serves as a guide to study and model interactions since it consists in representing main situations' components and relations between them. It also helps ensure a common operational picture between stakeholders and thus to support situation awareness by unifying situations' understanding. Moreover, requirements for effective communication in rescue operations were identified based on the proposed model and its main elements. Regarding the rescue model as well as the proposed requirements, an approach based on activities and procedures derived from rescue operations applied in France has been presented. However, the obtained results can be adopted for use and application in other countries since the main elements, parameters, and requirements are generic.

As future work, we aim to validate the proposed model with a real case study in order to evaluate it by domain experts. Moreover, we will investigate the specifications and architecture of Rescue MODES in a way to meet the proposed requirements. To this end, we will study multi-agent architectures and their benefits in the design of the system. In addition, we will absolutely complete the proposed models by other models oriented for systems' specifications such as agent-based models. Moreover, we will inspect how mobile devices like smartphones can be integrated in these operations and accepted by actors due to their usefulness. This work will include a thorough study on the availability, integrity, and confidentiality of exchanged data. 


\section{REFERENCES}

Appligos. (n.d.-a). Appli-Carto. Retrieved from http://www.appligos.fr/produits-et-references/samu-smur/appli-carto/ (accessed 17 July 2019 ).

Appligos. (n.d.-b). Appli-SAMU. Retrieved from http://www.appligos.fr/produits-et-references/samu-smur/applisamu/ (accessed 17 July 2019 ).

Appligos. (n.d.-c). Appli-Semba. Retrieved from http://www.appligos.fr/produits-et-references/samu-smur/appli-semba/ (accessed 12 July 2019).

Azcona, E. R. (2013). DISASTER Data Interoperability Solution At Stakeholders Emergency Reaction 285069. Retrieved from http://disasterfp7.eu/sites/default/files/D3.22.pdf (accessed 5 april 2019).

Bachimont, B., Isaac, A., \& Troncy, R. (2002). Semantic Commitment for Designing Ontologies: A Proposal. In International Conference on Knowledge Engineering and Knowledge Management. Springer, Berlin, Heidelberg, 2002. pp. 114-121.

Barros, R., Kislansky, P., Salvador, L., Almeida, R., Breyer, M., \& Gasparin, L. (2015). EDXL-RESCUER ontology: Conceptual model for semantic integration. In Proceedings of the 12th International Conference on Information Systems for Crisis Response and Management (ISCRAM 2015).

Cazeneuve, B., \& Touraine, M. (2015). "Inter-Ministerial Circular DGOS / R2 / DGSCGC No. 2015-190 of 5 June 2015 on the application of the decree of

24 April 2009 on the implementation of the referential relating to the organisation of personal assistance and the urgent medical help," "Circulaire interministérielle DGOS/R2/DGSCGC no 2015-190 du 5 juin 2015 relative à l'application de l'arrêté du 24 avril 2009 relatifà la mise en œuvre du référentiel portant sur l'organisation du secours à personne et de l'aide médicale urgente”, BO Santé, Protection sociale, Solidarité n² 2015/7 du 15, page 1, 2015.

Chaawa, M., Thabet, I., Hanachi, C. \& Ben Said, L. (2017). Modelling and simulating a crisis management system: an organisational perspective. Enterprise Information Systems, Vol 11, $\mathrm{N}^{\circ}$ 4. pp. 534-550.

Chehade, S., Matta, N., Pothin, J.-B., \& Cogranne, R. (2018). Data Interpretation Support in Rescue Operations: Application for French Firefighters. In Proceedings of the 15th International Conference on Computer Systems and Applications (AICCSA 2018). IEEE. pp. 1-6.

Chehade, S., Matta, N., Pothin, J.-B., \& Cogranne, R. (2019). Situation Representation and Awareness for Rescue Operations. In Proceedings of the 16th International Conference On Information Systems For Crisis Response And Management (ISCRAM 2019). pp. 980-991.

Décugis, J.-M., \& Pelletier, E. (2018). Après la mort d'un soldat du feu, la lettre d'indignation du patron des pompiers de Paris. Retrieved from http://www.leparisien.fr/faits-divers/la-lettre-d-indignation-du-patron-des-pompiers-de-paris-12-09-2018-7886160.php (accessed 30 July 2019)

Dourish, P. \& Bellotti, V. (1992). Awareness and coordination in shared workspaces. In Proceedings of the 1992 ACM conference on Computer-supported cooperative work (CSCW 1992).

Elmhadhbi, L., Karray, M. H. \& Archimède, B. (2018). Towards an Interoperable Operational Emergency Response System for Large-Scale Situations : POLARISC. In Proceedings of the 15th International Conference On Information Systems For Crisis Response And Management (ISCRAM 2018). pp. 1-8.

Endsley, M. R. (2001). Designing for situation awareness in complex systems. In Proceedings of the 2nd International Workshop on Symbiosis of Humans, Artifacts and Environment. pp. 1-14.

Fenech, M. G. \& Pietrasanta, M. S. (2016). Rapport d'enquête relative aux moyens mis en œuvre par l'Etat pour lutter contre le terrorisme depuis le 7 janvier 2015. $\mathrm{N}^{\circ}$ 3922. Vol. 2 . Retrieved from http://www.assemblee-nationale.fr/14/pdf/rap-enq/r3922-t2.pdf (accessed 1 August 2019).

Glassey, O. (2008). A case study on process modelling — Three questions and three techniques. Decision Support Systems, Vol 44, N 4. pp. 842-853.

Gruber, T. R. (1993). A translation approach to portable ontology specifications. Knowledge Acquisition, Vol 5, No 2. pp. 199-220.

Javed, Y., Norris, T., \& Johnston, D. (2011). Ontology-Based Inference to Enhance Team Situation Awareness in Emergency Management. In Proceedings of the 8th International ISCRAM Conference (ISCRAM 2011). pp. 1-9.

Li, X., Liu, G., Ling, A., Zhan, J., An, N., Li, L., \& Sha, Y. (2008). Building a practical ontology for emergency response systems. In Proceedings of the 2008 International Conference on Computer Science and Software Engineering, Vol. 4. pp. 222-225.

Mallek, S., Sauvagnargues, S., Tena-Chollet, F., Charrel, B., \& Arnaud, I. (2016). Contribution to the Definition of a New Type of More Technological Ambulance: Use Case of French Civil Security Ambulances. Open Journal of Safety Science and Technology. pp. 126-142.

Matheus, C. J., Kokar, M. M., Baclawski, K., Letkowski, J. A., Call, C., Hinman, M. L., Boulware, D. M. (2005). SAWA: an assistant for higher-level fusion and situation awareness. Multisensor, Multisource Information Fusion: Architectures, Algorithms, and Applications, Vol. 5813. pp. 75-85.

Meissner, A., Wang, Z., Putz, W., \& Grimmer, J. (2006). MIKoBOS-a mobile information and communication system for emergency response. In 3rd International Conference on Information Systems for Crisis Response and Management (ISCRAM 2006). pp. 92-101.

Musen, M. A. (2015). The Protégé project: A look back and a look forward. AI Matters. Vol. 1, № 4. pp. 4.

Nomadeec. (n.d.). Nomadeec Mobile Telemedicine. Retrieved from http://www.nomadeec.com/plaquettesWeb/Plaquette Nomadeec Paramed.pdf (accessed 11 July 2019).

Nunavath, V., \& Prinz, A. (2015). Norwegian emergency management process by using business process modeling notation. In Proceedings of the 8th IADIS International Conference on Information Systems (IS 2015).

Pease, A., Niles, I., \& Li, J. (2002). The Suggested Upper Merged Ontology : A Large Ontology for the Semantic Web and its Applications. Imagine, vol. 28, pp. 7-10.

Saoutal, A., Cahier, J. P., \& Matta, N. (2014). Modelling the communication between emergency actors in crisis management. In 2014 International Conference on Collaboration Technologies and Systems (CTS 2014). pp. 545-552

Séguret, F. (2018). SINUS, pour le suivi en temps réel des victimes de catastrophes et des grands événements. Retrieved from https://www.secourisme.net/spip.php?article607 (accessed 15 July 2019).

Sis. (n.d.-a). ARTEMIS et SDIS Admin : solutions de gestion des SDIS. Retrieved from http://www.sis-france.com/fr/solutions/sdis/ (accessed 15 July 2019).

Sis. (n.d.-b). Centaure15 : solution de régulation. Retrieved from http://www.sis-france.com/fr/solutions/sante/ (accessed 16 July 2019 ).

Steen-tveit, K., \& Radianti, J. (2019). Analysis of Common Operational Picture and Situational Awareness during Multiple Emergency Response Scenarios. In Proceedings of the 16th International Conference On Information Systems For Crisis Response And Management (ISCRAM 2019). pp. 199-208

Systel. (n.d.). Les pompiers connectés. Retrieved from https://www.systel-sa.fr/les-pompiers-connectes/ (accessed 11 July 2019).

TplSystemes. (n.d.). Pilot Mobile. Retrieved from https://tplsystemes.com/product/47 (accessed 12 July 2019).

Wooldridge, M., Jennings, N. R., \& Kinny, D. (2000). The Gaia Methodology for Agent-Oriented Analysis and Design. Authonomous Agents and multi-agent systems, $\mathrm{Vol} 3, \mathrm{~N}^{\circ}$ 3. pp.285-312.

Yang, L., Prasanna, R., \& King, M. (2009). On-Site Information Systems Design for Emergency First Responders. Journal of Information Technology Theory and Application JITTA. Vol. 10, $\mathrm{N}^{\circ} 1$, pp. 23.

Yu, K., Wang, Q., \& Rong, L. (2008). Emergency ontology construction in emergency decision support system. In Proceedings of 2008 IEEE International Conference on Service Operations and Logistics, and Informatics. Vol. 1. pp. 801-805. 